\title{
The Contribution of the Integrated Quality Management System to Whole School Development
}

\author{
Dr Rabichund S \\ Prof Steyn GM \\ Department of Educational Leadership and Management, \\ University of South Africa, P O Box 392, Pretoria 0003, South Africa \\ Email: Steyngm1@unisa.ac.za
}

\section{Doi:10.5901/mjss.2014.v5n4p348}

\begin{abstract}
The effectiveness of educational reform initiatives depends on the impact of the policy on the whole school. The Integrated Quality Management System (IQMS - 2005) in South Africa is a performance management system aimed at improving the quality of education. This article reports on the investigation done for a doctoral thesis (Rabichund 2011). The study adopted a mixed-method approach within purposefully selected schools. Its aim was to explain the impact of the Integrated Quality Management System on Whole School Development in the light of the national policy. The findings reveal educators views on IQMS and the impact of IQMS on schools. The difficulty with IQMS implementation was that it did not necessarily translate easily into a plan of action in the schools that led to effective whole school development. An ongoing challenge therefore exists for South African schools in their search for quality, in particular in the effective implementation of IQMS for the sake of Whole School Development.
\end{abstract}

Keywords: performance appraisal, whole school development, professional development

\section{Introduction}

During the last decade there has been a growing interest in improving the quality of education both nationally and internationally (Biputh \& McKenna, 2010; De Witt 2009; Greyling, 2009; Motala, 2009; Soyisile, 2007; Stewart, 2011). This interest resulted in introducing new educational reforms through government policies, which focused specifically on school improvement (Bubb \& Earley, 2009). Such reforms stimulated the development of numerous strategies directed towards improving the quality of learning and teaching in classrooms and engaging teachers in transforming education. Although the pursuit of quality education occurs world-wide, the building of a quality education system is even more important in a developing country such as South Africa (Greyling 2009; Motala 2009:235; Ramnarain 2010: xvii, Gallie 2007) where reports on the quality of education in South Africa are negative and show 'downward trend on a yearly basis' (De Witt 2009:619). To address this issue of quality of education The National Policy on Whole School Evaluation states that an effective evaluation and monitoring process 'is vital to the improvement of quality and standards of performance in schools' and that the 'findings must be used to re-orientate efforts towards improving the quality and standards of individual and collective performance' (Department of Education 2000:7).

Inherent in this statement is the role of an appraisal system in monitoring the performance and quality of teachers. In the efforts on improving schools the quality of teachers has been identified as having the single, biggest influence on the quality of education and student performance (Stewart, 2011; Yaric, 2009). In line with this view Greyling (2009: 434) asserts that 'enhancing learning in South Africa's schools could be considered as the most valuable contribution educators can make to sustain democracy and minimize inequalities'.

In South Africa the apartheid education ended in 1994 although many problems related to schooling still exist (De Witt, 2009). During the apartheid era external evaluation was done through inspection (Biputh \& McKenna, 2010). Teachers experienced this form of evaluation as unpleasant and viewed it with suspicion. This led to the breakdown of the culture of teaching and learning in schools (Biputh \& McKenna, 2010). As a result the Department of Education radically shifted the direction of education with a series of policy initiatives and legislation, with clear implications for managing the education system (Department of Education, Task Team on Education Development, 2000). One of the initiatives was the emergence of an appraisal system for educators. Consensus for the new educator appraisal model, 
the integrated quality management system (IQMS) was reached in August 2003 (Resolution 8 of Education Labour Relations Council, 2003). IQMS is regarded as a means of assessing the quality of education at individual and school level against certain prescribed standards and emerged after the ineffective implementation of Performance Management (PM), Developmental Appraisal System (DAS) and Whole School Evaluation (WSE) respectively (Ramnarain, 2010i).

Since the introduction of IQMS in 2003, little empirical research was carried out to establish whether the scheme addresses what it was intended to. Jansen's study (2004) provides an overview of the way in which the South African government set up evaluation policies within post-apartheid institutions. Smith and Ngoma-Maema's study (2003) describe the development of a quality assurance system by means of an emerging framework for the analysis of quality assurance systems. The study of Zamandosi (2008) focused on the experience of principals and staff regarding the implementation of quality assurance policies in KwaZulu Natal while Biputh and McKenna (2010) attempted to show the tensions in the integrated quality management system as perceived by teachers. Ramnarain's study (2010) aimed at examining the extent to which the IQMS promotes professional development among teachers and the extent to which it advocates accountability. This article builds on these studies and investigated how IQMS impacted on whole school development in schools.

\section{Theoretical Framework}

Studies on the appraisal process predominantly identify two approaches to appraisal, namely the professional and accountability models which show the distinctiveness of the model (Biputh \& McKenna, 2010; Monyatsi, 2003: Ramnarain 2010). The professional model of staff appraisal has, as point of departure, the belief that teachers desire to improve their teaching performance to enhance student learning (Monyatsi, 2003). The model is regarded as a two-way process between the appraiser and appraisee in which teachers are engaged as full participants. The accountability model of appraisal reflects the traditional approach that emphasises inspection and control (Monyatsi, Kamper \& Steyn, 2006).

Performance appraisal for the purpose of this study was defined as an ongoing activity of managing and evaluating educators' performance against certain criteria. Performance appraisal serves at least two purposes; professional development of teachers and school improvement (Zhang \& Ng, 2011; Teddle, Stringfield \& Burdett, 2003). Teddle et al. (2003) regard school improvement and accountability as two linked, but distinct goals since schools and teachers are accountable for public funds.

IQMS with its managerialist orientation is regarded as a performance measurement strategy designed to improve the quality of education in schools framed by accountability, performance standards, performance criteria, and financial incentives based on educators' performance (Rabichund, 2011). According to Ramnarain (2010:1ix) demands for a stronger system of accountability often result from bureaucratic authority instead from teachers themselves and is therefore viewed as 'an imposition on teachers'. Such a system of accountability may serve the interests of government and not necessarily the professional interests of teachers who desire to address their students' needs and interests (Ramnarain 2010:1ix). Moreover, Ramnarian (2010:1x) views 'IQMS as an attempt by government to control their work in the wake of globalization and the accompanying discourse of managerialism'. This view is supported by Biputh and McKenna (2010:284) analysis of IQMS: 'IQMS results in an emphasis on accountability over development which increases teacher resistance by evoking their memories of the inequitable inspection system of the past thereby restricting the system's ability to enhance the quality of South African education'.

As a second, but linked process to IQMS Whole School Evaluation (WSE) is viewed as the process to determine the performance of an entire school by collecting and analysing information to ascertain the quality of education at a particular school or institution (Department of Education, 2001). School development as envisaged by WSE is a key element in the evaluation of schools which means that WSE is closely aligned with school development.

Whole school development is an instrument that endeavours to improve the academic, infrastructural, social and security environment in schools by focusing on leadership, governance, quality of teaching, professional development, school safety and discipline, learner support systems, motivation and teambuilding, extra and co-curricular activities, parental involvement and maintenance of school structures (Adopt a School, 2009). It is built on structures, practices and processes that promote collaboration, communication, self-reliance and collective leadership. Furthermore, it is viewed as a means for transformation which includes all the essential elements undertaken by the school to nurture an environment that is conducive to development and also involves all stakeholders in aspects of school development. 


\section{Research Design}

This study adopted a mixed-method design that is 'eminently suited for exploring variations in the construction of meaning of concepts in relation to how respondents, for instance, make sense of their experiences or report on attitudes in interviews or questionnaires, respectively' (Bergman, 2010:172). As such an explorative, descriptive and contextual research design was used to investigate the impact of IQMS on Whole School Development. To reach the mentioned aim, the research was done in the following two phases: In phase 1 questionnaires were administered to principals and educators in KwaZulu-Natal in order to elicit their views on the IQMS while semi-structured interviews were conducted with principals, Senior Management Team members and educators in phase 2. Phase 2 attempted to attain a better understanding of the views of participants, the problem under investigation and to increase the credibility and authenticity of the findings.

A purposive sampling of ten schools with maximum variance (McMillan \& Schumacher 2006) was selected: five primary schools and five secondary schools. School A (a primary school, a Quintile 2 school); School B (a primary school, a Quintile 2 school); School C (a primary school, a Quintile 1 school); School D (a primary school, a Quintile 2 school) and School E (a primary school, a quintile 2 school). The secondary schools in the study (schools F, G, H, I were Quintile 2 schools while School J was a Quintile 4 school). In South Africa quintiles are used to rank the schools according to their socio-economic status. Quintile 4 and 5 schools are viewed as "rich" schools while quintile 1 and 2 schools are regarded as the poorest schools (CREATE, 2009:3). From each of the ten selected schools, participants were purposively selected to ensure that information-rich participants were included in the study (Lindof and Taylor, 2002).

The quantitative data in phase 1 was measured at ordinal level and descriptive statistics were used during the interpretive phase. The descriptive statistics assisted in organising the data in so that it gave meaning while it also provided accurate, objectively determined values that could easily be interpreted and compared (Keller \& Warrick, 2003). In the qualitative phase interviews were conducted to gain a clear understanding of participants' views and experiences regarding the contribution of IQMS to WSD. All interviews were recorded and transcribed. The qualitative data analysis involved the following processes: the reading/rereading, describing, classifying and interpreting (Gay \& Airasian, 2000).

In this study the interpretive, constructivistic framework which focuses on experience and interpretation was used in researching the contribution of the IQMS to WSD (Nieuwenhuis, 2010). In employing this framework, certain principles such as an adherence to systematic observation of complex phenomena, the use of multiple methods and triangulation of findings, valuing qualitative methods for their contribution to analysis and striving for logical explanation based on the evidence from analysis (Lindlof \& Taylor 2002).

The study considered the following ethical measures: avoiding research sites where participants may have felt forced to participate in the study; respecting the participants' privacy by protecting their anonymity and identify; treating all participants with the necessary respect and securing their co-operation; and informing participants from the start that they were at liberty to withdraw from the study at any time (Bogdan \& Biklen, 2003).

\section{Discussion of Results}

Chatsworth, a large township in Durban, South Africa, was created as a result of Group Areas Act during apartheid. It was designated for the Indian population only. Certain parts of Chatsworth still have extreme poverty although there is a large middle class and also some wealthy areas. As a result of its history, Chatsworth still has a predominantly Indian population (Pithouse, 2001). Schools in the study were predominantly under-resourced and were located in disadvantaged communities. In addition the schools were extremely old and had not been refurbished due to lack of funds at the time of the study.

\subsection{Educators' views of integrated quality management system}

The results in Phase 1 covered the educators' perceptions of IQMS, the factors impacting on IQMS and the contribution of IQMS to Whole School Development (see Table 1). 
Table 1: Factors impacting on IQMS Phase 1

\begin{tabular}{lcc}
\hline \multicolumn{1}{c}{ Description } & $\begin{array}{c}\text { Mean } \\
\text { Score }\end{array}$ & $\begin{array}{c}\text { Rank } \\
\text { Order }\end{array}$ \\
\hline Both management and staff should support the IQMS philosophy strongly. & 3.39 & 1 \\
The principal and staff should work closely together. & 3.35 & 2 \\
It is easier for a small school (less than 1000 students) to implement IQMS effectively. & 3.29 & 3 \\
A shared professional culture among staff who have the same goals and values is important & 3.08 \\
The type of training (staff meetings/formal professional development programmes/informal discussions) & 3.04 \\
influences the effective implementation of IQMS. & 2.48 \\
Education policies (mandates) influence the effective implementation of IQMS. & 3.10 \\
Average & 5 \\
\hline
\end{tabular}

Respondents believed that a shared professional culture was important and received a mean score of 3.08. They indicated that the type of training influenced the effective implementation of IQMS (a mean score of 3.04). This moderate rating indicates that respondents were still coming to grips with IQMS. Many educators found themselves so entrenched in their former teaching practices and many found it difficult to break that mould that had been established. Training regarding IQMS also seemed to be a debatable issue since the training was limited and did not equip educators successfully to manage IQMS. A significant number of respondents (mean score of 2.48), did not believe that education policies influenced the effective implementation of IQMS. All selected schools at the time of the survey had undergone IQMS and it was likely that very little, if any, outcome of the process was accomplished explaining their responses.

Findings from phase 2 support the findings in phase 1. Educators believed that constant changes, such as the induction of IQMS created a potential for disequilibrium within classrooms and schools. As a result the feelings and the energy levels of educators rose and fell, which also affected their personal lives.

The following categories relating to educators views of IQMS were identified: Increase in paper work; policing educator work; undermining educator competency; scoring and monetary incentives; and ineffective time frame of the appraisal process.

\subsubsection{Increase in paper work}

Some participants revealed a lack of enthusiasm for IQMS since it lead to more 'paper work'. Educators spend more time on record keeping instead of effective teaching, which should be the principal responsibility. Although educators were not averse to keeping necessary records, some of them raised the concern that the IQMS process placed greater demands in excessive and unnecessary record-keeping. One educator succinctly expressed her view:"Educators who have just joined the profession find record-keeping daunting because their focus is now diverted." Moreover educators were dissatified about the so called "patrolling, controlling and hegenomy" surrounding their teaching practice. Furthremore, educators felt that new reforms impacted seriously on issues of classroom discipline, management and overall educator administrative work. Although the main objective of the Department of Education regarding IQMS "is to ensure quality public education for all and to constantly improve the quality of learning and teaching" (ELRC 2003:3) most educators viewed the IQMS as a bureaucratic, paper exercise rather than a reflective and developmental process to improve the quality of teaching.

The findings are supported by Chisholm and Hoadley's (2005:29) study that shows that IQMS led to the intensification of educator's work and also increased their workload and that IQMS increased bureaucratic accountability rather than promoting educator professionalism. This bureaucratic accountability also had an element of inspecting educators' performance.

\subsubsection{Policing educator work}

Educators believed that IQMS was not about their professional development but rather about inspection justifying educators trepidation and anxiety about IQMS. As such the IQMS system had the contrary effect from the one it was intended to have. Teachers felt that IQMS focussed on monitoring the performance of educators to meet the expectations of the Department of Education and that IQMS was forced upon schools.

What became apparent in the interviews was that educators did not fully understand that IQMS was meant to be a developmental. Educators merely complied with the IQMS procedure because it was something that had to be done as 
one educator explained: "For me it is like a formality, a farce and the reports are generally a misrepresentation of what really occurs. This whole process is a mockery."

Jansen's critique (2004: 64) had been proven right in this study that although on the surface the IQMS attempts to empower educators and emphasizes educator development, it was considered to be a bureaucratic control mechanism. Educators' views were also confirmed by Welton (2001:182) that the "policing network" was synonymous with an authoritarian style. The aforementioned was endorsed by many educators as they felt that the IQMS was simply a system of control cleverly masked as a professional development tool.

\subsubsection{Undermining eductor competency}

The ensuing discussion was confirmed during the quantitative data analysis concerning educator competency where $71 \%$ of the educators felt that they were proficient and the IQMS was debasing and insulting their potential as educators. The participants explained that they were professionals but that IQMS did not allow educators to exercise their professionalism. One of the educators explained: "IQMS undermines my capacity as an educator. I feel demoralized, discouraged and humiliated as the system tends to cast a slur on all educators". This view was supported by a SMT member: "IQMS tends to ignore the fact that educators have undergone training and are well equipped to enter any classroom and deliver.

Educators believed that they did not need an instrument to measure how well they taught. Furthermore, IQMS made educators feel incompetent and inadequate although they considered themselves to be 'seasoned educators'who were well trained with a thorough knowledge of their respective learning areas. A number of educators also expressed their annoyance with the Department of Education for 'undermining' their potential as educators.

Educators saw the IQMS as punitive and they resisted it and discredited it (Patel 2001: 8). Samuel's (2004) position was supported by educators in the study since they also felt deskilled, disempowered and deprived of professional esteem and did not have a positive professional image. Educators were in acquiescing with Reddy's (2005) assertion that the IQMS did little to empower educators and it did not address the multitude of problems that were encountered.

\subsubsection{Scoring and monetary incentives}

The major concern raised was that if the Development Support Group (DSG) downgraded the scores of a particular educator it could result in a dispute between the DSG and this educator since it meant that the $1 \%$ increase for the educator was rejected. The monetary incentive thus was viewed as a shortcoming in the IQMS system since it could create hostility and resentment among staff members. In this regard an educator said: "Nepotism, preferential treatment, bias cannot be overlooked. Remember one's colleagues are one's friends and friends do not let friends down... This clearly defeats the purpose of IQMS."

It was clear from educators' responses that transparency did not manifest itself during the implementation of IQMS since they experienced bias, favouritism and inconsistent application of criteria during the appraisal process. Many educators regarded the system in the scoring of the IQMS as distorted which could obliteratethe goal of the process. A valid point was raised by one of the SMT members who suggested the following: "If IQMS was conducted by experts, specialists, authoritative figures like subject advisers, SEM's [Superintendent of Education Management] or even lecturers it would validate the process".

Principals and SMT members felt that while the intention of the IQMS was positive, the use of scores changed the focus from professional development to pay progression. One principal explained:

"Scores that educators receive are questionable and do not assist in the development of educators. Scores are inflated and not a genuine reflection of an educator's performance -these scores to me, are not justified... Awarding a score of 4 implies that the educator is well developed".

Although educators criticised IQMS, the only appealing facet of IQMS for them was the financial stipend. This implies that a value system needs to be inculcated among educators to apply themselves sincerly in the classroom with the main purpose of improving the quality of education and not focus on self interest only. As educators enunciated this was not taking place and the IQMS was constructed to simply comply on surface level.

Some educator's views corresponded with that of Fitz-Gibbon (1996) that performance related pay is a waste of public money. He further adds that if feedback alone produces improvements, why was performance-related pay 
necessary? Related to the issue of scoring and monetary incentives is the issue of time frames in the IQMS process.

\title{
4.1.5 Ineffective time frame of the appraisal process
}

Principals indicated that although the educators were not unwilling to be appraised, the common concern was that of time constraints which had an adverse effect on IQMS. In this regard one principal stated:

\begin{abstract}
"Appraisal has to be resourced in terms of time and expertise... While appraisal is being conducted, educators are inundated simultaneously with various other issues such as curriculum transformation, co-curricular activities, disciplinary problems and a host of other activities. In view of the above the school has to establish and prioritise in terms of time and resources what appraisal objectives need to be targeted".
\end{abstract}

The way in which IQMS was implemented also raised concern among participants. Educators disclosed the fact that IQMS was ineffective and an exercise in futility since a one day observation cannot develop an educator effectively. The issue of time was accurately clarified by one of the principals: "The time frame is problematic especially with large numbers... Educators spend a maximum of five to ten minutes when evaluating their peers because they also have classes which are left unattended".

Moveover, participants believed that educators usually go to extreme lengths to impress the DSG members for that particular day ensuring the use of teaching aids and other resources which were otherwise not used in other lessons. A proposal forwarded by the educators was that class visits should be conducted throughout the year and that the onceoff observation of IQMS should be aborted.

The findings confirm theproclamation of Patel (2001:2) that IQMS can often be so perverse that good 'window dresses' were rewarded for their showpersonship rather than for their contribution to the education system. This was endorsed by an educator who added: "Having records up to date and showing evidence of work does not mean that the educator is teaching effectively. It is a mere form of window dressing". Nolan and Hoover (2004) also support the view of participants that effective appraisal depends on observing educators over an extended timeframe and not once or twice. When educators are appraised more often, a comprehensive picture of their teaching performance can be obtained with a view to assist them in their professional development.

The IQMS as a quality and performance management system in essence aims at developing the school.

\subsection{The impact of IQMS on the whole school development}

The following section of the questionnaire (Phase 1) focused on the perceptions of educators regarding the impact of IQMS on the school with special emphasis on the improvement of teaching since the introduction of IQMS, the improvement of learning among students since the introduction of IQMS, the improvement of relationships between teachingstaff and learners; staff members and staff and parents since the introduction of IQMS (Table 2).

Table 2: Impact of IQMS

Responses

Frequency Percentage

The quality of the teaching has improved since the introduction of IQMS

29

13.2

The quality of learning among students has improved since the introduction of IQMS.

$59 \quad 26.5$

Relationships among staff members have improved since the introduction of IQMS.

$35 \quad 15.8$

The relationship among teaching staff and learners has improved since the introduction of IQMS.

The relationship between staff and parents has improved since the introduction of IQMS.

Missing system

25

15.8

Total

$59 \quad 26.5$

The responses in Table 2 indicate that the IQMS did not impact strongly on educators and especially the relationship between educators and students. A percentage of 13.2 regarding the improvement of the quality of teaching since the introduction of IQMS is meager and does not augur well for IQMS. The quality of teaching appears to be compromised in the face of other factors such as the increase in paper work which is a priority and the quality of teaching is marginalised. The $26.5 \%$ response to the improvement of the quality of learning among students is regarded as negative since the main aim of IQMS is to improve the quality of learning which This implies that IQMS did not achieve the desired outcom. 
The improvement in the relationship among staff, staff members and learners and staff members and parents was inconsequential as reflected in the $15.8 \%, 11.5 \%$ and $26.5 \%$ responses respectively.

Respondents'experience of IQMS revealed the following results: The majority of respondents considered IQMS to be time consuming as reflected in the $39.5 \%$ response. The IQMS was no easy feat for educators as is reflected in the difficulty of the process being categorised as $2^{\text {nd }}(28.8 \%)$. The $3^{\text {rd }}$ shortcoming of IQMS is clearly revealed in the $27.5 \%$ response to the question concerning IQMS as presenting a challenge for the school. The last two points mentioned is a lucid implication of the exigent nature of IQMS. What is quite explicit from the overt $2.6 \%$ and $2 \%$ response for IQMS being worthwhile for the school and IQMS being worthwhile for professional development respectively is that the process was of little or no consequence to the educators. Many participants in the interviews did not see IQMS as the main vehicle to whole school development nor did they see it as a vehicle for instructional improvement.

The data analysis in Phase 2 reveals that participants had various views on the impact of IQMS on whole school development.

\subsubsection{IQMS and teaching for whole school development}

The IQMS policy requires educators to radically change the ways in which they carried out their teaching responsibilities for the sake of whole school development. According to principal, the general purpose of staff appraisal in the IQMS was to ensure that educators keep abreast of the changes or trends in education and that they do not stagnate. Another purpose of appraisal was to enable educators to meet new educational and societal challenges and to ensure professional growth.

Some schools were not conscious of the 'whole school' notion suggested by the IQMS policy, while others viewed 'whole school' as an ideal towards which they wished to move. Those who were familiar with the policy believed that introducing IQMS required schools to produce development plans for the school. They also had to develop whole school policies which also called for a fundamental change in the attitudes of many educators. In their views these educators referred to whole school development as an ideal. This was clearly expressed in the following statement made by a principal: "Whole school development is what we are working towards. It is not something that is easy to achieve. It takes time and effort... Schools are constantly developing." A 'whole school' was not something the staff of the selected schools felt they had realised as a SMT member stated: "IQMS has not taken us [the school] a step forward."

Two secondary school principals announced that their schools were meeting all expectations of the Department since IQMS had been implemented. At one of the secondary schools twelve level one educators were promoted to senior educators and four level one educators were promoted to master educators. One of these high school principal said: "The IQMS and WSE [whole school evaluation] programmes can produce compelling results such as substantial gains in learner achievement, but these designs must be well implemented - if not well implemented then schools run into problems." This school obtained $100 \%$ pass rate in the senior certificate examinations for seven consecutive years and the principal attributed the success to higher instructional quality which positively influenced student performance.

Supporting the quantitative data in phase 1, there were different views regarding the impact of IQMS on school development. Participants acknowledged that developing a 'whole school' was a difficult enterprise. Working together provided opportunities for closer professional relations amongst the staff and greater mutual appreciation of strengths, but in the process fundamental differences in value and practice between educators constantly emerged. The aforementioned was confirmed in the following by an educator: "At our school clash of personalities creates a major problem affecting progress. Some educators are so stubborn in their outlook that they refuse to accept alternatives when it comes to teaching". Learning about one another's work during the IQMS process exposed staff to differences in their teaching practice which stimulated not only discussion but often also led to disagreement. When the latter occurred it was destructive since professional relations were harmed which, in turn, demonstrated to everyone else that the school was not a 'whole' institution.

On the contrary, to some educators 'whole schools' meant communities with respected leaders whose members shared the same educational beliefs and intentions and in which the majority attempted to put these beliefs into action in broadly similar ways. These educators believed that IQMS urged them to work together and to develop collegiality, collective involvement of educators in school-based review and development. Moreover, two out of the ten schools were familiar with the actions and purposes of other colleagues and experienced a sufficient degree of similar thinking to work collaboratively. There was a willingness among colleagues in these schools to engage collaboratively which was considered as a hallmark of educators' professional maturity. One educator succinctly explained this: "Previously it was educators working on their own, in isolation with the sole intention of completing the syllabus." In these schools educators 
felt free to make many individual decisions, were conscious of a considerable measure of classroom autonomy and felt valued for their particular contributions to the school community.

Although the principals valued and respected individuals they also monitored the extent to which staff enacted agreed policies in their classrooms. They conceded that classrooms were difficult to enter because of the autonomy of educators to resist appraisal. Moreover, participants in some schools believed that IQMS obscured educators' purposes by diverting their attention from plans which they had already made. Other schools, however, believed that they were flourishing slowly but surely as a possible consequence of IQMS.

A number of principals and SMT members believed that IQMS promoted co-curricular and extra-curricular activities in schools and this improved the quality of teaching and learning which led to whole school development. One principal said:

"Co-curricular and extra-curricular activities now receive far more attention than previously. Educators showed reluctance previously when it came to extra-curricular activities but with the IQMS there seems to be a new found interest and enthusiasm as the IQMS process is compelling educators to become more accountable in aspects other than curricular activities".

With the introduction of IQMS educators were cognizant of the fact that their contribution to the school would influence their rating and as such displayed an enthusiasm to engage themselves in co-curricular and extra-curricular activities.

Professional development is regarded as crucial in the development of the school in totality. The next section deals specifically with the concept of professional learning as significant in ensuring whole school progression.

\subsubsection{Professional learning as key to whole school development}

The tradition of autonomy, individualism and self-reliance had been ingrained for a number of years which presented difficulties in breaking the practice. Both educators and SMT members saw professional learning as the key to whole school development and as the main way to improve the quality of children's education. As individual educators initiated and supported developments, they increased their own professional knowledge and skills, their understanding of educational issues involved, and their appreciation of how others might benefit from their development. There was evidence to suggest that professional learning had not always been as highly valued by the staff of the ten schools as it was at the time of the study.

The behavior and attitudes of principals, deputy principals and heads of department significantly contributed towards growing importance of professional learning as a key factor in the school's development. It was the desire of principals and educators to improve students' learning experiences by increasing their 'ownership' of the curriculum and their commitment to professional learning as the key to whole school development. Factors that assisted in increasing the capacity of educators in the selected schools to engage in professional learning were the many opportunities and means that existed for them to learn both within and outside the schools which often took place under favourable conditions and the fact that educators were highly motivated to develop and learn. As such whole school development could not be seen as separate from the learning of individual educators.

Educators felt individually responsible for the well-being and learning of the students that they taught. Their sense of personal responsibility for the education of 'their' students and the belief that they were in charge of it encouraged them to seek ways to improve their own practice. It implied 'acquiring fresh knowledge', for example in subjects like science and technology or in mastering new approaches to teaching such as in reading and spelling. Educators' practice also changed in other fundamental ways. They were often faced with the need to reassess their own beliefs about the purposes and nature of education or to accept challenges regarding the values which shaped their perspectives and approach.

The SMT members in the selected schools felt responsible for the students and curriculum in their schools. They all had strong beliefs regarding the educational, moral and social purposes of schooling and consequently about the nature of the curriculum and the professional practice within their schools to enable whole school development. Consequently they sought to ensure that staff in their schools shared certain beliefs and values and also acted accordingly. The SMT members also demonstrated their personal commitment to professional learning by actively pursuing their own education, by talking to staff about what they learnt and by demonstrating their willingness to learn from others. One SMT member maintained: 
As an SMT member I stimulate, encourage and motivate my educators to involve themselves in IQMS and I make them see it as an instrument to bring about improvement in their teaching. I urge them to see IQMS in a positive light as a tool to develop them and not something to torture them... Teamwork is constantly encouraged, come up with innovations and develop an understanding between the educators in the school.

The example of SMT members conveyed two other messages to their schools: that professional development of individuals could benefit everybody and that staff members could contribute to and assist each other's learning.

Educators maintained that IQMS was difficult to implement and that it created new problems in the classrooms. As such educators in this study identified their professional development needs in the area of classroom management and discipline, as well as administrative or paperwork duties. They also identified the need for parental involvement as a crucial challenge that would assist in improving the performance of students.

For some educators the procedures of IQMS were viewed as essential for quality improvement and accountability and considered it valuable since IQMS acted as 'checks and balances' for educators. A SMT member enunciated:

"The IQMS process in our school to a certain extent terminated procrastination- in other words - what needed to be done was done immediately and not left for a later date because one knew of the inspections and ensured that it was attended to. This guaranteed that even the so called 'shirkers' and educators who are generally ill-prepared for lessons to do their job."

Since educators were aware of supervision, they ensured that their work was up to date. Educators otherwise tended to under-perform in their duties if they know that they are not going to be monitored. IQMS with its monitoring system compelled educators to become accountable in the sense that they engaged in better planning and preparation of lessons, kept meticulous educator portfolios and learner records.

However, some SMT members believed that while IQMS made most educators accountable, they were concerned was that in spite of the 'checks and balances' in the IQMS process, a minority of educators continued with their tardiness as one SMT member expressed:

"A dedicated, committed educator will be able to perform and deliver in the classroom at any time - be accountable at all times. However, educators who lack motivation and focus and are apathetic will not be accountable. These are the educators who are like parasite and rely completely on their team for providing everything."

The findings are in line with that of a study of teacher appraisal in Kenya (Odhiambo 2005). Odhiambo (2005) concluded that one of the perceived benefits of appraisal is that it acts as a reminder for the educators of what they are expected to do and this is confirmed in the following assertion by an educator: "IQMS is important because it is only human nature to forget things sometimes and IQMS is there as a constant reminder that certain things need to be done and keeps educators on their toes - to ensure checks and balances".

It is necessary to understand why South African educators think the way they do about their professional development needs, but it is also 'difficult to talk about South African educators in universal terms [given their wide disparities]' (Harley and Parker 2000: 32). This is because educators have to face the implementation challenges of new sophisticated IQMS without much support for the Department of Education. School change and reform are neither easy nor quick.

The constant push for reform creates what has been known as 'reform fatigue' and is associated with disillusionment (Hargreaves \& Goodson, 2006) although the literatures on the history of school reform indicate that resistance to change is an ongoing phenomenon. Hargreaves and Fink's (2006:11) belief that the development of 'slow knowing' which is a key characteristic of sustainable organisational reform practice was also pertinent in this study. Educators believed that it takes a lot of time to implement something new and effectively into existing school practices.

An individual educator is not able to function independently. Collaborative efforts and assistance are required for success in any institution. The following section examines the reciprocal relation between educators in the promotion of whole school development.

\subsubsection{Interdependence fostering whole school development}

If a school is considered to be a holistic web where everything is interconnected and interdependent, a change in one part of the school will not only rely on other parts of the school to support it, but may also have positive or negative or unanticipated effects on the whole. Individual educators dealt with personal problems such as illnesses. Absence from 
school because of school excursions, personal appointments, attending workshops or interviews also provided interruptions that disrupted the work of other educators. In the case of loss of staff, replacement by temporary appointments was required. These changes influenced the school when teams were created or meetings were scheduled. Educators' roles' and responsibilities also changed as a result of this. This impacted directly and indirectly on IQMS and whole school development.

\section{Conclusion}

Improving the quality of schooling in South Africa is of the utmost importance. Implementing IQMS has been a reform initiative to address this dire need. Policies do not explicitly explain what should be done; they create circumstances in which the range of options available for implementation is narrowed and particular outcomes or goals are stipulated. It therefore explains why the effective implementation of IQMS implementation is riddled with intricacy and complexity, as indicated in the study.

The difficulty with IQMS implementation was that it did not necessarily translate easily into a plan of action in majority of the schools that led to effective whole school development. Some schools valued the challenges and opportunities provided by IQMS and believed that it assisted in whole school development, while other schools lacked the apparent certainty on the process and were still grappling with its implementation. This is where policy makers have incorrectly presupposed that each school will be able to apply the principles of IQMS appropriately to meet the particular circumstances of individual schools.

Based on the study the following recommendations are made:

- Schools need to be optimally resourced for policies, in this case for IQMS to be implemented successfully. Every role player should be extensively capacitated for effectual performance of roles by engaging people possessing adeptness and expertise on IQMS implementation with the goal of improving the school as a whole. It is recommended that the Department of Education employ the services of private providers and form partnerships with reliable providers.

- Professional interchange, collaboration and networking is recommended since it provides schools with the opportunity to learn from each other and to solve problems collectively.

- The recommendation is that the district office should take the responsibility of monitoring and co-ordinating all development implemented in its schools. IQMS should not be partnered with educators' remuneration.

- To avoid partiality, nepotism and prejudice as is currently present when educators are assessed by colleagues, the recommendation is that IQMS be conducted by the SEM, examiners and subject advisers. Feedback needs to be provided to foster teaching practice at schools. Educators need to know where their weaknesses lie so that appropriate measures can be taken to engender development.

An ongoing challenge is presented to South African schools in their search for quality, in particular in the effective implementation of IQMS for the sake of Whole School Development. In conclusion, we agree with the comment of Jansen (2004:64): that 'The only way in which to reverse this institutional attitude towards external evaluation and support in South Africa is to demonstrate slowly and systematically that such interventions indeed function in the interests of teachers.

\section{References}

Bergman, M.M. (2010). On Concepts and Paradigms in Mixed Methods Research. Journal of Mixed Methods Research, 4(3), $171-175$.

Biputh, B., McKenna, S. (2010).Tensions in the quality assurance processes in post-apartheid South African schools. Compare, May, 40( 3), 279-291.

Bogdan, R.C. \& Biklen, S.K. (2003). Qualitative research for education: an introduction to theory and methods. (4th ed.). Boston: Allyn \& Bacon.

Brown, B. (2004). Teacher migration to Botswana: Implication for Human Resources Management in Education. D.Ed. thesis. Pretoria: University of South Africa.

Bubb, S. \& Earley, P. (2009). Leading staff development for school improvement. School Leadership and Management, February, 29(1), 23-37.

Craft, A. 2000. Continuing professional development. $2^{\text {nd }}$ edition. USA: Routledge \& Falmer.

CREATE. (Consortium for Research on Education, Access, Transitions \& Equity). (2009). No-fee schools in South Africa. Policy Brief, number 7.August. [Online] Available: http://www.CREATE-rpc.org (October 31, 2013)

Department of Education, (2000). The national policy on whole school evaluation. Government Gazette 423, no. 22512. Pretoria: Government Printer. 
Department of Education. (2001). Evaluation guidelines and criteria for the Whole School Evaluation Policy. Pretoria: Government Printers.

De Witt, M.W. (2009). Emergent literacy: why should we be concerned? Early Child Development and Care, July, 179(5), 619-629.

Education Labour Relations Council (ELRC). (2003). Collective Agreement Number 8 of 2003, 23 August 2003. Integrated Quality Management System. Pretoria: ELRC

Gallie, M. (2007). The implementation of Developmental Appraisal Systems in low-functioning South African schools (Abstract). Ph.D, University of Pretoria, South Africa.

Gay, L.R. \& Airasian, P. (2000). Educational Research. (6 $6^{\text {th }}$ ed.). USA: Prentice Hall.

Greyling, A.J. (2009). Reaching for the dream: quality education for all. Educational Studies, October, 35(4):425-435.

Hargreaves, A. (2003). Teaching in the knowledge of society. education in the age of insecurity. Buckingham: Open University Press.

Jansen, J.D. (2004). Autonomy and accountability in the regulation of the teaching profession: A South African case study. Research Papers in Education, 19(1), 51-66.

Keller, G. \& Warrick, B. (2003). Statistics for Management and Economics. Pacific Grove,California: Thompson Learning, Inc.

Lindof, T.R. \& Taylor, B.C. (2002). Qualitative communication research methods. (2nd ed.). Thousand Oaks, CA: Sage.

Lodge, C. \& Reed, J. (2003). Transforming school improvement now and for the future. Journal of Educational Change, 4(1), 45-62.

McMillan, J.H. \& Schumacher, S. (2006). Research in education. Evidence-based inquiry. (6th ed.). Boston: Pearson Education.

Monyatsi, P.P. (2003). Teacher appraisal: An evaluation of practices in Botswana secondary schools. Unpublished DEd thesis. Pretoria: University of South Africa.

Monyatsi, P., Kamper, G. \& Steyn, T. (2006). Teacher appraisal in Botswana secondary schools: a critical analysis. South African Journal of Education, May, 26(2), 215-228.

Motala, S., Dieltiens, V \& Sayed, Y. (2009). Physical access to schooling in South Africa: mapping dropout, repetition and age-grade progression in two districts. Comparative Education, May, 45(2), 251-263.

Nieuwenhuis, J. (2010). Introducing qualitative research. In K. Maree (Ed). First steps in research (pp46-68). Pretoria: Van Schaik Publishers.

Rabichund, S. (2011). The Contribution of the Integrated Quality Management System to Whole School Development. DEd thesis. Pretoria: University of South Africa.

Rademeyer, A. (2007). Pandorwys die armsteskoolgroepe. Beeld, 27 September: 5. Republic of South Africa.

Ramnarain, S. (2010). The Integrated Quality Management System: Exploring the tension between Accountability and Professional Development. PhD: University of KZN.

Smith, W.J. \& Ngoma-Maema, W.Y. (2003). Education for all in South Africa: Developing a national system for quality assurance. Comparative Education, Aug, 39(3), 345-65.

Soyisile, N.A. (2007). (Abstract) The management tasks of principals in promoting professionalism amongst educators in the Eastern Cape Province. D.Ed. University of South Africa.

Stewart, V. (2011). Improving teacher quality around the world, Phi Delta Kappan, May, 92(8), 93,95.

Teddle, C., Stringfield, S. \& Burdett, J. (2003). International comparisons of the relationships aomongeducaitonaleffectivness, evaluation and improvement variouables: An overview. Journal of Personnel Evaluation in Education, 17(1), 5-20.

USAID. (2010). Whole School Approach: Communities as Change Agents... [Online] Available: kenya.usaid.gov/programs/educationand-youth/327. (October 28, 2010).

Yaric, E. (2009). The appraisal of teachers' performance and its impact on the mutuality of principal-teacher emotions. School Leadership and Management, Nov. 29(5), 445-461.

Zamandosi, C.V. (2008). The management of the implementation of Quality Assurance policies: The case of Integrated Quality Management System in secondary schools in KwaZulu Natal. M Ed dissertation in Education Management. Pretoria: University of South Africa.

Zhang, X.F. \& Ng, H.M. (2011). A case study of teacher appraisal in Shanghai, China: In relation to teacher professional development. Asia Pacific Education Review. [Online] Available: DOI 10.1007/s12564-011-9159-8 (October 31, 2013) 